13,01

\title{
Туннелирование и инжекция в ферромагнитных структурах InGaAs/GaAs/(Ga,Mn)As и InGaAs/n+-GaAs/(Ga,Mn)As
}

\author{
(c) Е.И. Малышева ${ }^{1}$, М.В. Дорохин ${ }^{1}$, А.В. Здоровейщев ${ }^{1}$, М.В. Ведь ${ }^{2}$ \\ ${ }^{1}$ Научно-исследовательский фризико-технический институт \\ Нижегородского государственного университета им. Н.И. Лобачевского, \\ Нижний Новгород, Россия \\ ${ }^{2}$ Нижегородский государственный университет им. Н.И. Лобачевского, \\ Нижний Новгород, Россия \\ E-mail: malysheva@phys.unn.ru
}

Проведено исследование спиновых светоизлучающих диодов на основе гетероструктур с квантовой ямой $\mathrm{InGaAs} / \mathrm{GaAs}$ и инжектором в виде ферромагнитного слоя (Ga,Mn)As. Показана возможность управления эффективностью спиновой инжекции электронов в структуре с туннельным барьером $(\mathrm{Ga}, \mathrm{Mn}) \mathrm{As} / n^{+}-\mathrm{GaAs}$ путем варьирования параметров $n^{+}$-GaAs. Обсуждаются механизмы управления спиновой инжекцией, связанные с термической активацией и туннелированием носителей.

Работа выполнена в рамках реализации государственного задания (проекты № 8.1054.2014/К, № 3.285.2014/K, № 3423) Минобрнауки РФ, при поддержке РФФИ (гранты № 15-02-07824_а, 15-38-20642 мол_а_вед и 16-07-01102_a), а также при поддержке гранта Президента РФ (МК-8221.2016.2).

\section{1. Введение}

Структуры на основе разбавленных магнитных полупроводников находят применение в современной электронике и оптоэлектронике как элементы новых приборов на спин-поляризованных носителях [1,2]. Слои $(\mathrm{Ga}, \mathrm{Mn}) \mathrm{As}$, в частности, являются перспективным видом ферромагнитных инжекторов для спиновых светоизлучающих диодов вследствие наилучшей совместимости с основным материалом оптоэлектроники - GaAs [1,2]. Особенностью инжекторов $(\mathrm{Ga}, \mathrm{Mn}) \mathrm{As}$ является дырочная проводимость [2]. Эта особенность обусловливает наличие двух способов инжекции спин-поляризованных носителей в активную область спиновых светоизлучающих диодов: спиновая инжекция дырок в прямосмещенных $p-i-n$-диодах (Ga,Mn)As/i-GaAs/n-GaAs [3] и более pacпространенная схема инжекции спин-поляризованных электронов в структурах с туннельным барьером (Ga,Mn)As $/ n^{+}-\mathrm{GaAs} / n-A_{3} B_{5} / i-A_{3} B_{5} / p-A_{3} B_{5}$ [4-6]. В указанной структуре связанные электроны инжектируются из валентной зоны (Ga, $\mathrm{Mn}) \mathrm{As}$ ( $p$-типа проводимости) через туннельный барьер, образованный обратносмещенным $p^{+} / n^{+}$-переходом (Ga, Mn) As $/ n^{+}-\mathrm{GaAs}$, в зону проводимости $n-A_{3} B_{5}$. Спиновая инжекция электронов считается более предпочтительным вариантом в силу большего значения времени спиновой релаксации электронов по сравнению с аналогичной величиной для дырок (что повышает эффективность работы спиновых светоизлучающих диодов) [1,5]. В то же время первые работы по исследованию диодов с туннельным барьером показали низкую либо сопоставимую эффективность спиновой инжекции электронов по сравнению со схемами на основе инжекции дырок $[4,5]$. Подобное несоответствие, вероятно, связано с сильным легированием слоев $n$-типа проводимости в структуре с туннельным барьером, что обусловливает спиновое рассеяние инжектированных электронов при прохождении сильнолегированной области. В более поздних работах был предложен способ существенного (более чем на порядок) повышения степени циркулярной поляризации за счет использования специфического механизма термоэлектронной эмиссии и туннелирования связанных электронов в гетероструктурах (Ga,Mn)As $/ n^{+}-\mathrm{GaAs} / n-\mathrm{AlGaAs} / i-\mathrm{GaAs} / p$-AlGaAs. B paбoтах $[7,8]$ с этой целью выполнялось варьирование параметров легирования структур (толщины и уровня легирования туннельного слоя $n^{+}$-GaAs) и обеспечивались условия образования небольшого потенциального барьера для валентных электронов в $(\mathrm{Ga}, \mathrm{Mn}) \mathrm{As}$. В настоящей работе представлены результаты исследований гетероструктур (Ga,Mn)As $/ n^{+}-\mathrm{GaAs} / n$-GaAs/ $i$-InGaAs $/ p$-GaAs и показано, что механизм термоэлектронной эмиссии и туннелирования связанных электронов может быть реализован и для данных структур, что проявляется в сильной зависимости эффективности спиновой инжекции от параметров туннельного слоя $n^{+}$-GaAs. В работе приводятся результаты исследований циркулярно поляризованной электролюминесценции спиновых светоизлучающих диодов на основе указанных структур. Рассмотрена зависимость степени циркулярной поляризации (являющейся мерой эффективности спиновой инжекции) от параметров туннельного слоя. Кроме того, выполнено сравнение с контрольными структурами со спиновой инжекцией дырок (Ga,Mn)As $/ n^{+}$-GaAs. Показано, что термически активированное туннелирование связанных электронов обеспечивает повышение эффективности спиновой инжекции по сравнению с характерным значением для контрольной структуры. 


\section{2. Методика эксперимента}

Отличием от известных работ является использование для формирования структур комбинированного метода газофазной эпитаксии из металлоорганических соединений и гидридов (или МОС-гидридной эпитаксии - МОСГЭ) и импульсного лазерного осаждения (ИЛО) [9]. Полупроводниковые структуры с туннельным слоем формировались на подложке $p$-GaAs (100) методом МОСГЭ при температуре $600^{\circ} \mathrm{C}$. Последовательно выращивались буферный слой $p$-GaAs, квантовая яма (QW) $\operatorname{In}_{x} \mathrm{Ga}_{1-x} \mathrm{As}: \mathrm{C}$ (концентрация $p \sim 8 \cdot 10^{17} \mathrm{~cm}^{-3}$, ширина $d_{\mathrm{QW}}=10 \mathrm{~nm}$, содержание In $x \approx 0.12$ ), тонкий слой нелегированного GaAs $(d \approx 6 \mathrm{~nm})$, слой $n$-GaAs с градиентным легированием толщиной $90 \mathrm{~nm}$ и сильнолегированный слой $n^{+}$-GaAs. Варьировалась толщина сильнолегированного (туннельного) слоя $d_{\text {tun }}=8$, $10,12,15,20$ и $30 \mathrm{~nm}$ при уровне легирования $n_{\mathrm{tun}} \sim 10^{19} \mathrm{~cm}^{-3}$ (структуры № 1-6), а также изменялся уровень легирования туннельного слоя при $d_{\mathrm{tun}}=10 \mathrm{~nm}$ до $n_{\text {tun }} \sim 7 \cdot 10^{18} \mathrm{~cm}^{-3}$ (структура № 7). Параметры исследованных структур приведены в таблице. На следующей стадии эпитаксиального процесса методом лазерного распыления $\mathrm{Mn}$ - и GaAs-мишеней при температуре $340^{\circ} \mathrm{C}$ были выращены слой $\mathrm{Ga}_{0.83} \mathrm{Mn}_{0.17} \mathrm{As}$ толщиной $90 \mathrm{~nm}$ нелегированный слой $\mathrm{GaAs}$ толщиной $6 \mathrm{~nm}$ для предотвращения окисления ферромагнитного полупроводника. Снижение температуры выращивания необходимо для минимизации диффузии Мn из легированного слоя. Дополнительные детали технологии изготовления структур описаны в $[9,10]$. Ферромагнитные свойства аналогичных слоев $(\mathrm{Ga}, \mathrm{Mn}) \mathrm{As}$, выращенных на подложках $i$-GaAs, были изучены в [11]. Слои $(\mathrm{Ga}, \mathrm{Mn})$ As имели $p$-тип проводимости $\left(p \sim 10^{19}-10^{20} \mathrm{~cm}^{-3}\right)[11]$.

Также были сформированы контрольные структуры $p-i-n$-диодов на основе $(\mathrm{Ga}, \mathrm{Mn})$ As. На подложках

Параметры светоизлучающих диодов с туннельным барьером, содержащих слои разбавленного магнитного полупроводника

\begin{tabular}{c|c|r|r|c|c}
\hline $\begin{array}{c}\text { Номер } \\
\text { структуры }\end{array}$ & Подложка & $\begin{array}{c}d_{s}, \\
\mathrm{~nm}\end{array}$ & $\begin{array}{c}d_{\mathrm{tun}}, \\
\mathrm{nm}\end{array}$ & $\begin{array}{c}n_{\mathrm{tun}}, \\
\mathrm{cm}^{-3}\end{array}$ & $\begin{array}{c}\text { Толщина } \\
\text { ферромагнитного } \\
\text { слоя, } \mathrm{nm}\end{array}$ \\
\hline 1 & $p$-GaAs & 94 & 8 & $10^{19}$ & 90 \\
2 & $p$-GaAs & 96 & 10 & $10^{19}$ & 90 \\
3 & $p$-GaAs & 98 & 12 & $10^{19}$ & 90 \\
4 & $p$-GaAs & 101 & 15 & $10^{19}$ & 90 \\
5 & $p$-GaAs & 116 & 30 & $10^{19}$ & 90 \\
6 & $p$-GaAs & 106 & 20 & $10^{19}$ & 90 \\
7 & $p$-GaAs & 96 & 10 & $7 \cdot 10^{18}$ & 90 \\
$C$ & $n$-GaAs & 15 & - & - & 90
\end{tabular}

Примечание. Параметр $d_{s}$ в структурах с туннельным барьером соответствует общей толщине слоев GaAs между квантовой ямой InGaAs и инжектором (Ga,Mn)As, $d_{\text {tun }}$ - толщина $n^{+}$-GaAs туннельного слоя, $n_{\text {tun }}-$ концентрация доноров в туннельном слое $n^{+}-\mathrm{GaAs}$, $C$ соответствует контрольной структуре $p-i-n$-диода с инжектором (Ga,Mn)As в качестве слоя $p$-GaAs.

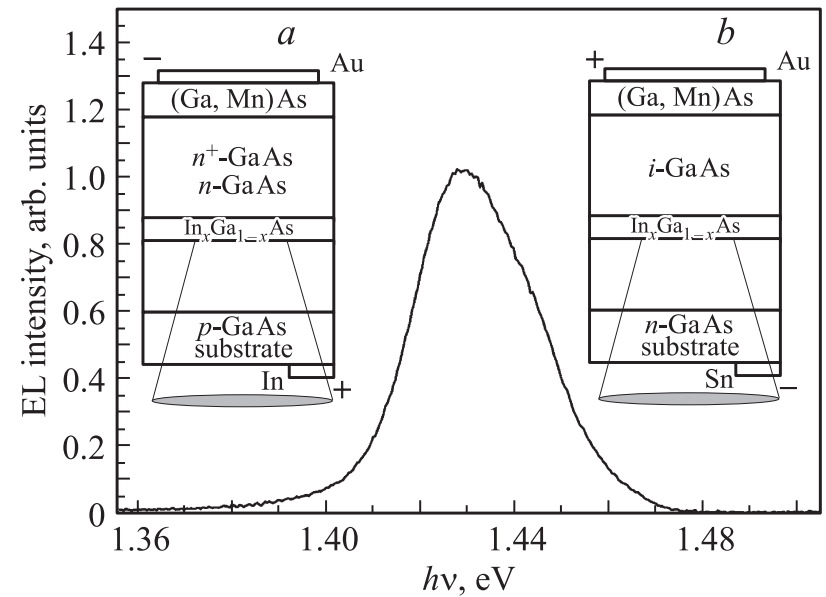

Рис. 1. Спектр электролюминесценции структуры № 1 (см. таблицу), измеренный при температуре $77 \mathrm{~K}$ и токе диода $5 \mathrm{~mA}$. На вставках показаны схематические изображения исследованных структур $(a)$ и контрольной структуры $(b)$.

$n$-GaAs при температуре $600^{\circ} \mathrm{C}$ методом МОСГЭ последовательно выращивались буферный слой $n$-GaAs, квантовая яма $\operatorname{In}_{x} \mathrm{Ga}_{1-x}$ As (с аналогичными параметрами) и спейсерный слой нелегированного GaAs толщиной $30 \mathrm{~nm}$. Затем формировались слой $\mathrm{Ga}_{0.83} \mathrm{Mn}_{0.17} \mathrm{As}$ толщиной $90 \mathrm{~nm}$ и нелегированный слой $\mathrm{GaAs}$ толщиной $6 \mathrm{~nm}$ методом ИЛО, параметры технологии при этом не отличались от указанных в предыдущем случае. Для формирования диодной структуры на поверхность образцов наносился омический Аu-контакт методом электронно-лучевого испарения в вакууме. Методами фотолитографии и химического травления изготавливались меза-структуры диаметром $500 \mu \mathrm{m}$. Схемы исследованных структур представлены на вставках $a$ и $b$ к рис. 1 .

На диодах были выполнены исследования электролюминесценции (ЭЛ) при температуре измерений, равной $77 \mathrm{~K}$, а также циркулярно поляризованной электролюминесценции при температуре $10 \mathrm{~K}$. Степень циркулярной поляризации ЭЛ $\left(P_{\mathrm{EL}}\right)$ рассчитывалась по формуле

$$
P_{\mathrm{EL}}=\left(I^{1}-I^{2}\right) /\left(I^{1}+I^{2}\right),
$$

где $I^{1}, I^{2}$ - относительные интенсивности люминесценции, измеренные для света, поляризованного по левому $\left(I^{1}\right)$ и по правому $\left(I^{2}\right)$ кругу.

\section{3. Результаты исследований}

В режиме прямого смещения наблюдается электролюминесценция исследованных диодов, типичный спектр ЭЛ показан на рис. 1. В спектре присутствуют пики при энергии $1.41 \mathrm{eV}$, соответствующей основному переходу в квантовой яме $\mathrm{In}_{x} \mathrm{Ga}_{1-x} \mathrm{As} / \mathrm{GaAs}$. Показанный на рисунке спектр является типичным для диодов на основе гетероструктур с квантовой ямой $[10,12]$. Дополнительный анализ интенсивностей ЭЛ был выполнен для 


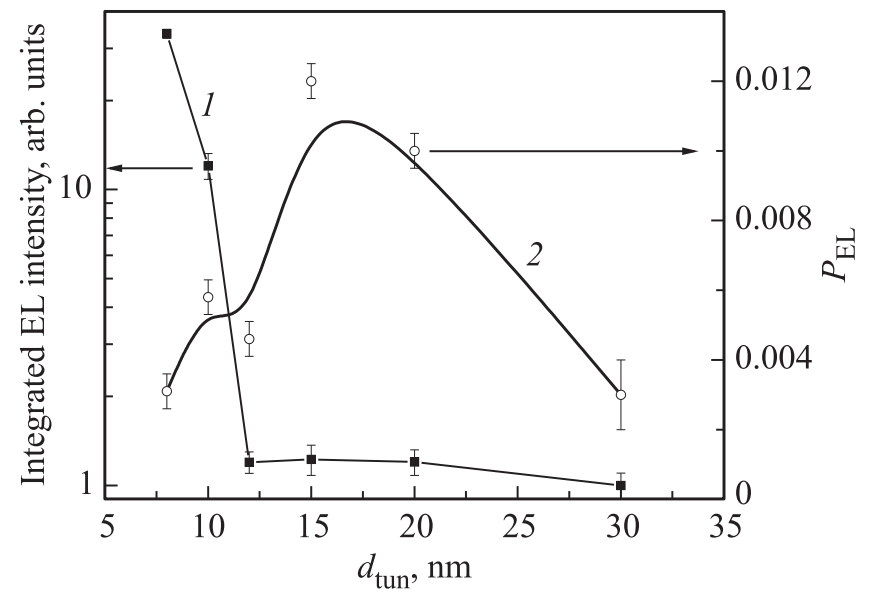

Рис. 2. Зависимость интенсивности ЭЛ для структур № 1-6 от толщины туннельного слоя $n^{+}$-GaAs, измеренная при температуре $77 \mathrm{~K}$ и токе диода $10 \mathrm{~mA}$ (кривая 1), и зависимость степени циркулярной поляризации ЭЛ для структур № 1-6 от толщины туннельного слоя $n^{+}$-GaAs, измеренная при температуре $10 \mathrm{~K}$ и токе диода $10 \mathrm{~mA}$ (кривая 2).

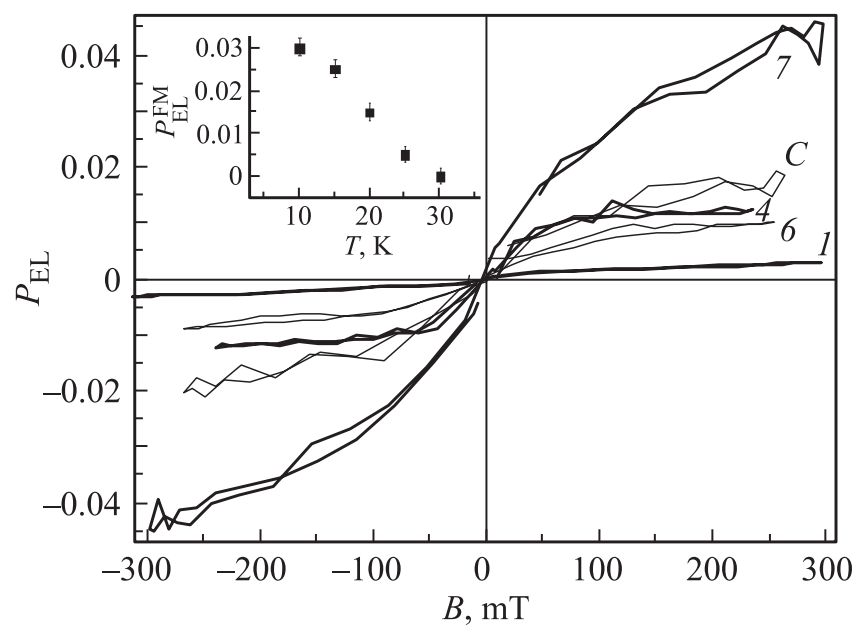

Рис. 3. Магнитополевые зависимости степени циркулярной поляризации ЭЛ для структур с различными параметрами туннельного слоя, измеренные при температуре $10 \mathrm{~K}$. Номера кривых соответствуют номерам структур в таблице. Кривая $C$ $p-i-n$-диод (контрольная структура). На вставке показана температурная зависимость ферромагнитной компоненты степени циркулярной поляризации $\left(P_{\mathrm{EL}}^{\mathrm{FM}}\right)$ для структуры № 7.

диодов, различающихся толщиной туннельного слоя. Зависимость интенсивности от $d_{\text {tun }}$ представлена на рис. 2 (кривая 1). При увеличении толщины туннельного слоя от 8 до $12 \mathrm{~nm}$ интенсивность электролюминесценции монотонно уменьшается более чем на порядок величины. Для $d_{\text {tun }}>12 \mathrm{~nm}$ интенсивность ЭЛ остается практически неизменной в пределах погрешности измерений.

При введении диодов во внешнее магнитное поле их электролюминесцентное излучение становится частично циркулярно поляризованным. Магнитополевая зависимость степени циркулярной поляризации для ис- следованных структур (см. таблицу) представлена на рис. 3. Вид зависимости подобен для всех исследованных структур и характерен для магнитополевой зависимости намагниченности слоев (Ga,Mn)As [2,10,11]: наблюдаются участок быстрого роста степени поляризации при $B<50-100 \mathrm{mT}$ и участок медленного роста $P_{\mathrm{EL}}$ при $B>50-100 \mathrm{mT}$. Сопоставление результатов исследований с данными, полученными для неферромагнитных структур в [10], позволяет заключить, что циркулярная поляризация ЭЛ определяется магнитными свойствами инжектора $(\mathrm{Ga}, \mathrm{Mn}) \mathrm{As}$. Участок быстрого роста $P_{\mathrm{EL}}$ связан с намагничиванием (Ga,Mn)As, участок медленного роста - с насыщением намагниченности в магнитном поле $\sim 100 \mathrm{mT}$ и зеемановским расщеплением уровней в квантовой яме. Значение $P_{\mathrm{EL}}$, таким образом, представляет собой сумму ферромагнитной компоненты и компоненты, связанной с зеемановским расщеплением уровней:

$$
P_{\mathrm{EL}} \approx P_{\mathrm{EL}}^{\mathrm{FM}}+P_{\mathrm{EL}}^{Z} .
$$

При повышении температуры измерений ферромагнитная компонента $P_{\text {EL }}$ уменьшается и при температуре $30 \mathrm{~K}$ становится равной нулю (вставка к рис. 3). Температура $30 \mathrm{~K}$ соответствует точке Кюри ферромагнитного (Ga,Mn)As, полученного методом ИЛО [11]. Зарегистрировано существенное различие значений степени циркулярной поляризации в зависимости от параметров исследованных структур. Наибольшее значение $P_{\mathrm{EL}} \approx 0.04$ получено для структуры с параметрами туннельного слоя $d_{\text {tun }}=10 \mathrm{~nm}, n_{\text {tun }} \approx 7 \cdot 10^{18} \mathrm{~cm}^{-3}$. Данное значение превосходит таковое для контрольной структуры $\left(P_{\mathrm{EL}}=0.02\right)$, при изменении параметров туннельного слоя значения степени циркулярной поляризации ниже, чем для контрольного $p-i-n$-диода.

Для анализа механизмов спиновой инжекции была построена зависимость степени циркулярной поляризации от толщины туннельного слоя, показанная на рис. 2 (кривая 2). В диапазоне $8 \leq d_{\text {tun }} \leq 12 \mathrm{~nm}$ степень циркулярной поляризации слабо зависит от толщины слоя. С увеличением толщины промежуточного слоя выше $12 \mathrm{~nm}$ степень циркулярной поляризации увеличивается, достигая максимума при $d_{\mathrm{tun}}=15 \mathrm{~nm}$, при дальнейшем повышении толщины туннельного слоя степень циркулярной поляризации монотонно уменьшается.

Перейдем к обсуждению результатов исследований. При обратном смещении $p-n$-перехода $\left(A_{3}, \mathrm{Mn}\right) B_{5} /$ $n^{+}$-GaAs в диоде с туннельным барьером из валентной зоны $\left(A_{3}, \mathrm{Mn}\right) B_{5}$ в зону проводимости GaAs протекает туннельный ток связанных электронов. Величина тока и его спиновая поляризация определяются зонной диаграммой структуры. На рис. 4 показаны схематические изображения зонных диаграмм исследованных структур. Толщина туннельного барьера для электронов зависит от изгиба зон обратносмещенного $p-n$-перехода и уровня легирования туннельного слоя. Отметим наличие энергетического разрыва $\Delta E$ между потолком валентной зоны (Ga,Mn)As и дном зоны проводимости $n$-GaAs (рис. 4, a,c). При приложении отрицательного электрического смещения к слою ( $\mathrm{Ga}, \mathrm{Mn}) \mathrm{As}$ его энергетические 

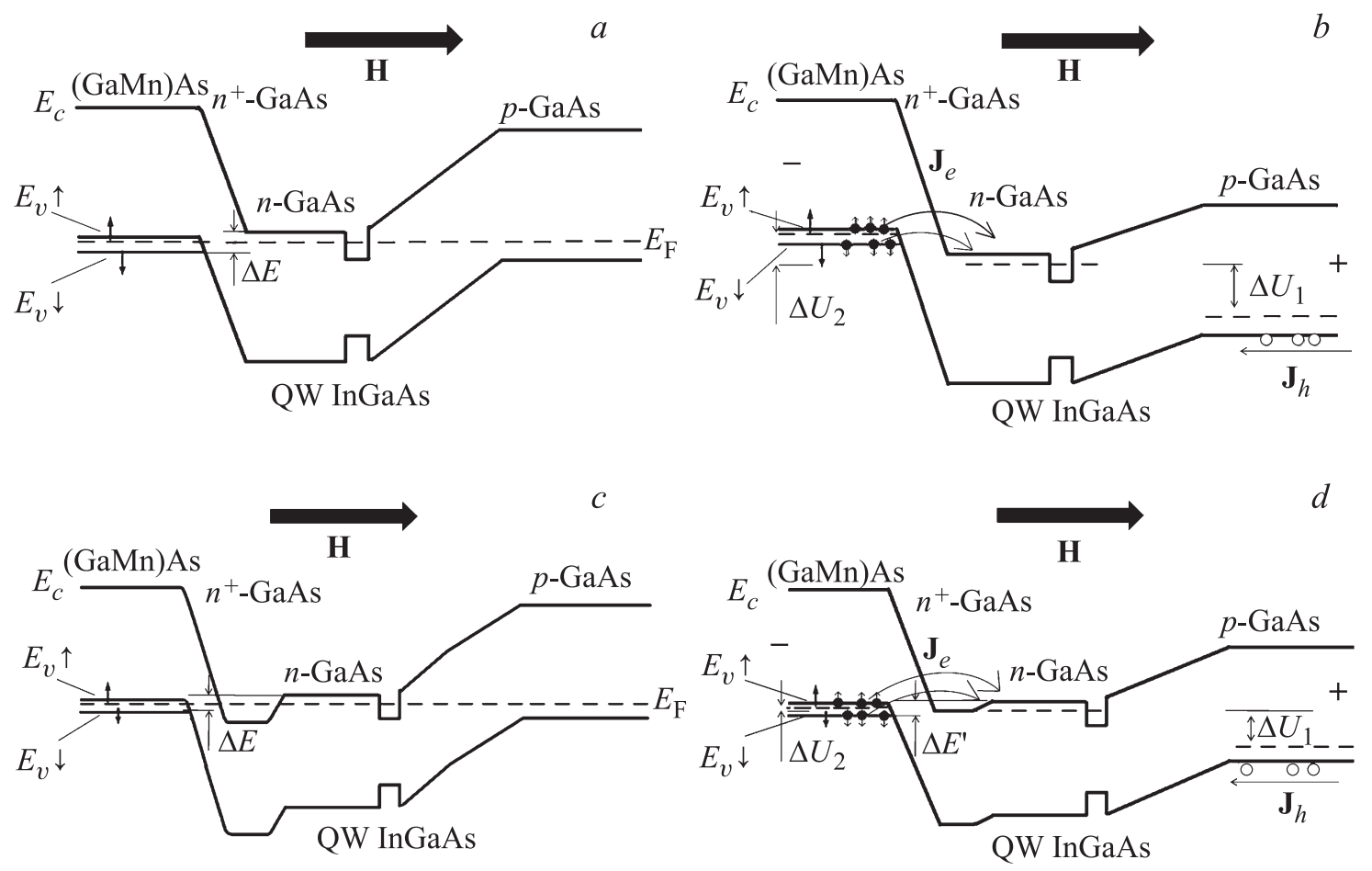

Рис. 4. Схематические изображения зонных диаграмм исследованных структур: $a, b-$ структур с низкой толщиной туннельного слоя $\left(d_{\mathrm{tun}}<12 \mathrm{~nm}\right), c, d-$ структур с высокой толщиной туннельного слоя $\left(d_{\mathrm{tun}}>15 \mathrm{~nm}\right) . a, c-$ без приложения электрического смещения, $b, d-$ с приложением электрического смещения в режиме туннельного диода. $\Delta U_{1}-$ падение напряжения на первом от подложки $p-n$-переходе при приложении электрического смещения; $\Delta U_{2}$ - падение напряжения на втором от подложки $p-n$-переходе при приложении электрического смещения; $J_{e}-$ ток электронов; $J_{h}$ - ток дырок; $\Delta E-$ величина барьера второго от подложки $p-n$-перехода без электрического смещения; $\Delta E^{\prime}$ - величина барьера второго от подложки $p-n$-перехода с приложением электрического смещения.

зоны смещаются вверх по энергии (при этом уменьшается величина энергетического зазора $\Delta E$ ), также уменьшается и толщина туннельного барьера (рис. $4, b$ ). Предположительно зонные диаграммы, представленные на рис. $4, a$ и $b$, соответствуют структуре с $d_{\text {tun }}=8 \mathrm{~nm}$. В рассматриваемом случае имеет место прямое туннелирование связанных валентных электронов из (Ga,Mn)As в зону проводимости $n$-GaAs, это обусловливает сравнительно высокую интенсивность электролюминесценции. При увеличении толщины туннельного слоя выше $15 \mathrm{~nm}$ формируется двойной потенциальный барьер: туннельный барьер на границе $(\mathrm{Ga}, \mathrm{Mn}) \mathrm{As} / n^{+}-\mathrm{GaAs}$, а также барьер $n^{+}$-GaAs $/ n$-GaAs, на формирование которого расходуется часть туннельного слоя (рис. 4,c). Электрическое смещение в режиме электролюминесценции приводит к уменьшению барьера $n^{+}-\mathrm{GaAs} / n-\mathrm{GaAs}$, при этом сохраняется разрыв $\Delta E^{\prime}$ между потолком валентной зоны (Ga,Mn)As и дном зоны проводимости $n$-GaAs (рис. 4,d). Указанный энергетический разрыв является потенциальным барьером для инжекции связанных электронов из валентной зоны ( $\mathrm{Ga}, \mathrm{Mn}) \mathrm{As}$, его наличие обусловливает существенное снижение интенсивности электролюминесценции диодов с $d_{\text {tun }}=10,12$, 15 и $30 \mathrm{~nm}$ по сравнению с наблюдаемой для структуры c $d_{\text {tun }}=8 \mathrm{~nm}$ при одинаковых токах диода (рис. 2, кривая 1). Величина барьера $\Delta E^{\prime}$ зависит от распределения напряжений между слоями структуры: переходом $n^{+}$-GaAs/n-GaAs, туннельным барьером, $p-n$-переходом $p$-GaAs $/ n$-GaAs. Предположительно, с ростом $d_{\text {tun }}$ величина $\Delta E^{\prime}$ несколько увеличивается, что обусловливает монотонное уменьшение интенсивности с увеличением толщины туннельного слоя (за исключением случая $\left.d_{\text {tun }}=30 \mathrm{~nm}\right)$.

Для циркулярно поляризованной электролюминесценции можно отметить, что сравнительно небольшие значения степени циркулярной поляризации характерны для структур со сравнительно высокой интенсивностью ЭЛ. В соответствии с рассмотренными выше зонными диаграммами (рис. $4, b$ ) для таких структур характерен не зависящий от температуры процесс инжекции спин-поляризованных электронов - прямое туннелирование из валентной зоны (Ga,Mn)As. Эффективность спиновой инжекции определяется расщеплением зоны для носителей с разным спином в $(\mathrm{Ga}, \mathrm{Mn}) \mathrm{As}$. В случае образцов $\mathrm{c} d_{\text {tun }}>12 \mathrm{~nm}$ значительную роль играют процессы термической активации электронов для преодоления барьера $\Delta E^{\prime}$. Поскольку энергии связанных электронов с „основным“ и „неосновным“ спином в (Ga,Mn)As различаются [8], вероятности надбарьерной эмиссии электронов с „основным“ и „неосновным“ спи- 
ном также будут различаться. Это вносит дополнительный вклад в спиновую поляризацию тока электронов и таким образом приводит к повышению $P_{\mathrm{EL}}$. Аналогичный механизм усиления степени циркулярной поляризации ЭЛ был рассмотрен для структур с туннельным барьером (Ga,Mn)As/GaAs/AlGaAs в [7,8]. Вклад такого механизма нивелируется при повышении температуры измерений, однако резкое уменьшение $P_{\mathrm{EL}}$, связанное с достижением точки Кюри, не позволяет провести подобное наблюдение. Зарегистрированное в эксперименте уменьшение степени циркулярной поляризации в диодах с толщиной туннельного слоя выше $15 \mathrm{~nm}$, вероятно, связано с повышением спинового рассеяния электронов при переносе в $n^{+}$-GaAs слое увеличенной толщины.

Сравнительно низкое значение степени циркулярной поляризации (до 0.015) может быть обусловлено рассеянием спин-поляризованных носителей при переносе в сильнолегированном слое $n^{+}$-GaAs. При этом описанные выше механизмы спиновой инжекции сохраняются и при незначительном снижении уровня легирования туннельного слоя. Поэтому уменьшение уровня легирования ниже $10^{19} \mathrm{~cm}^{-3}$ может привести к увеличению $P_{\mathrm{EL}}$. Такое увеличение было экспериментально зарегистрировано для структуры № 7 с пониженным уровнем легирования туннельного слоя (рис. 3, кривая 7). Наблюдаемое повышение степени поляризации предположительно связано с меньшим вкладом спинового рассеяния, чем в случае структур № 1-6, за счет меньшего уровня легирования $n^{+}$-GaAs [13].

В случае контрольной структуры на основе $p-i-n$ диода имеет место непосредственная инжекция спинполяризованных дырок в квантовую яму из намагниченного (Ga,Mn)As. Эффективность инжекции при этом определяется спиновым рассеянием на границе (Ga,Mn)As/i-GaAs, а также процессами спиновой релаксации дырок, которые обусловливают существенное снижение спиновой поляризации носителей по сравнению со случаем спиновой инжекции электронов.

\section{4. Заключение}

Таким образом, в работе приведено исследование эффектов спиновой инжекции электронов и дырок из ферромагнитного (Ga,Mn)As в активную область спинового светоизлучающего диода, сформированного комбинированным методом МОС-гидридной эпитаксии и ИЛО. Изучена зависимость эффективности спиновой инжекции электронов от параметров туннельного слоя. Показано, что при варьировании параметров туннельного слоя эффективность спиновой инжекции и степень циркулярной поляризации ЭЛ светоизлучающих диодов могут быть увеличены, что связывается с влиянием механизмов термической активации при туннелировании электронов из валентной зоны $(\mathrm{Ga}, \mathrm{Mn}) \mathrm{As}$ в зону проводимости $n$-GaAs.

\section{Список литературы}

[1] M. Holub, P. Bhattacharya. J. Phys. D 40, R179 (2007).

[2] T. Dietl, H. Ohno. Rev. Mod. Phys. 86, 187 (2014).

[3] D.K. Young, E. Johnston-Halperin, D.D. Awschalom, Y. Ohno, H. Ohno. Appl. Phys. Lett. 80, 1598 (2002).

[4] M. Kohda, Y. Ohno, K. Takamura, F. Matsukura, H. Ohno. Jpn. J. Appl. Phys. 40, L1274 (2001).

[5] D.K. Young, J.A. Gupta, E. Johnston-Halperin, R. Epstein, Y. Kato, D.D. Awschalom. Semicond. Sci. Technol. 17, 275 (2002).

[6] M. Oltscher, M. Ciorga, M. Utz, D. Schuh, D. Bougeard, D. Weiss. Phys. Rev. Lett. 113, 236602 (2014).

[7] M. Kohda, Y. Ohno, F. Matsukura, H. Ohno. Physica E 32, 438 (2006).

[8] P. Van Dorpe, Z. Liu, W. Van Roy, V.F. Motsnyi, M. Sawicki, G. Borghs, J. De Boeck. Appl. Phys. Lett. Appl. Phys. Lett. 84, 3495 (2004).

[9] Б.Н. Звонков, О.В. Вихрова, Ю.А. Данилов, Е.С. Демидов, П.Б. Демина, М.В. Дорохин, Ю.Н. Дроздов, В.В. Подольский, М.В. Сапожников. Опт. журн. 75, 6, 56 (2008).

[10] Е.И. Малышева, М.В. Дорохин, М.В. Ведь, А.В. Кудрин, А.В. Здоровейщев. ФТП 49, 1497 (2015).

[11] Б.Н. Звонков, О.В. Вихрова, Ю.А. Данилов, Ю.Н. Дроздов, А.В. Кудрин, М.В. Сапожников. ФТТ 52, 2124 (2010).

[12] G. Bacher, C. Hartmann, H. Schweizer, T. Held, G. Mahler, H. Nickel. Phys. Rev. B 47, 9545 (1993).

[13] Б.П. Захарченя, Ф. Майер. Оптическая ориентация. Наука, Л. (1989). 408 c. 